\title{
CLINICAL PRESENTATION AND PATHOLOGICAL STUDY OF HEAD AND NECK CANCER IN MALWA REGION OF PUNJAB
}

\author{
Jaskaranpreet Kaur1 ${ }^{1}$ J. P. Goyal2, Imrinder Kaur³, Saransh Goyal ${ }^{4}$ \\ 1 Junior Resident, Department of ENT, Government Medical College, Patiala. \\ ${ }^{2}$ Associate Professor, Department of ENT, Government Medical College, Patiala. \\ ${ }^{3}$ Senior Resident, Department of ENT, Government Medical College, Patiala. \\ ${ }^{4}$ Medical Officer, Community Health Centre, Badshahpur, Patiala, Punjab.
}

\begin{abstract}
\section{BACKGROUND}

Head and neck cancer is one of the most common cancers worldwide, and more than $90 \%$ of these tumours are squamous cell carcinomas. Oral cancer is the most common form of cancer and of cancer-related deaths in men in India. Tobacco and alcohol are the two strongest aetiological factors responsible for the development of head and neck squamous cell carcinoma, but in contrast younger patients often do not present these traditional risk factors, which leads to suspect other potential risk factors. Its high risk in the Indian subcontinent is related to the popularity of pan-tobacco (a combination of betel leaf, lime, areca nut and sun-cured tobacco) chewing in the region.

The objective of this study was aimed at analysing the incidence, aetiology and clinical presentation of head and neck carcinoma in our population and to evaluate the pathological findings and also the TNM staging in patients with head and neck carcinoma.
\end{abstract}

\section{MATERIALS AND METHODS}

We conducted a study on 150 diagnosed cases of head and neck cancer in the ENT Department of Government Medical College/Rajindra Hospital, Patiala, Punjab, India. Detailed history of the selected patients was taken and tumour data including site, subsite, grade and TNM stage were collected.

\section{RESULTS}

The maximum prevalence of patients with head and neck cancer was seen in the fifth decade (34.66\%) followed by sixth decade. The male-to-female ratio was 70:30. The highest incidence was in the persons belonging to labourer group followed by farmers and businessmen. Chronic smoking and drinking played a major role in causing cancer in these groups. Most frequent site involved was oral cavity $(39.33 \%)$ followed by oropharynx $(23.33 \%)$. In the oral cavity, tongue was the most common site followed by buccal mucosa, whereas in oropharynx base of tongue was the most common subsite followed by retromolar trigone. Maximum incidence of hypopharyngeal carcinoma, especially in the post-cricoid region was seen in female patients (84.6\%). Oral cavity cancers were most commonly presented with mass/growth followed by non-healing ulcers, whereas oropharyngeal cancers were most commonly presented with dysphagia followed by odynophagia. Majority of the patients presented with either welldifferentiated or moderately differentiated squamous cell carcinoma. Maximum number of patients presented with early tumour staging: $\mathrm{T}_{1}$ and $\mathrm{T}_{2}$.

\section{CONCLUSION}

This study was aimed at analysing the age, sex distribution, role of aetiological factors, extent and clinical presentation including site, subsite, TNM stage and histopathological grading. In non-smoking and non-drinking patients, sharp tooth, environmental smoke and occupational exposure may contribute to squamous cell carcinoma. High index of suspicion was required to diagnose these lesions early, even when history of smoking and drinking was absent.

\section{KEYWORDS}

Head and Neck, Squamous Cell Carcinoma, Oral Cavity.

HOW TO CITE THIS ARTICLE: Kaur J, Goyal JP, Kaur I, et al. Clinical presentation and pathological study of head and neck cancer in Malwa region of Punjab. J. Evolution Med. Dent. Sci. 2017;6(24):2020-2026, DOI: 10.14260/Jemds/2017/441

\section{BACKGROUND}

Head and neck cancer is one of the most common cancers found worldwide; more than $90 \%$ of these tumours are

Financial or Other, Competing Interest: None.

Submission 27-02-2017, Peer Review 14-03-2017,

Acceptance 17-03-2017, Published 23-03-2017.

Corresponding Author:

Dr. Imrinder Kaur,

D-10, Medical Campus,

Rajindra Hospital Patiala, Punjab.

E-mail:imrinder@hotmail.com

DOI: $10.14260 /$ jemds $/ 2017 / 441$
Squamous Cell Carcinoma (SCC) accounting for $5 \%$ to $10 \%$ of all new cancers in Europe and the USA. ${ }^{1}$ Head and Neck Squamous Cell Carcinoma (HNSCC) is an anatomically heterogeneous group of neoplasms arising from the mucosal surface of the oral cavity, oropharynx, hypopharynx, larynx, sinuses and other sites within the upper aerodigestive tract. The annual global incidence and mortality rates of HNSCC are 540,000 and 271,000, respectively. ${ }^{2}$ The International incidence of HNSCC (particularly of the oral tongue and oropharynx) has increased in young adults. ${ }^{3}$ Surprisingly, this increase has occurred concurrently with a decreasing prevalence of cigarette smoking in the general population; importantly, this observation would not be expected if the 
only primary risk factors for all HNSCC were alcohol and tobacco abuse. ${ }^{4}$ Incidence of oral cavity SCC and oropharyngeal SCC in patients under the age of 45 years increases for accounts for approximately $1 \%$ - 6\%.5,6 Tobacco and alcohol are the two strongest aetiological factors for the development of HNSCC, both independently and synergistically.7,8 They have long been implicated as the traditional risk factors for HNSCC in adults, regardless of age. A study evaluated betel-quid chewing as a risk factor for oral cancer and studies in India have examined the role of betel quid with and without tobacco in oral cancer cases, which concluded that adding tobacco to the betel quid significantly increased the risk of developing malignancies. ${ }^{9}$ In contrast to the 'typical' patient with HNSCC, younger patients do not often present the traditional risk factors of alcohol and/or tobacco exposure. This leads to suspect that other potential agents such as inherent genetic factors, viral infections and behavioural risk factors may be involved. ${ }^{4}$ Oral cancer is commonly seen in men of the developing countries. ${ }^{10}$ Oral cancer is the most common form of cancer and of cancerrelated deaths seen in men from India. ${ }^{10,11}$ Its high risk in the Indian subcontinent is related to the popularity of pantobacco chewing in the region. ${ }^{12}$ Oropharyngeal cancer forms the predominant group of cancer in the people from Punjab. Oropharyngeal cancers include cancer of the base of tongue, tonsil, soft palate cancer and NPC (Nasopharyngeal Carcinoma). NPC has been the second most common malignancy found in men for the past decade contributing to approximately $11 \%$ of all malignancies of the same sex. The significant difference in the geographical, ethnic and dietary habits within our country could predispose people from the north-eastern region of India for high incidence of NPC. Cancer of larynx (voice box) is one of the common cancers seen among men from the Indian subcontinent. Hypopharyngeal cancers are more common in men than in women. The most common site of origin of hypopharyngeal cancer is the pyriform sinus followed by the posterior pharyngeal wall and post-cricoid area $(20 \%-25 \%) \cdot{ }^{13}$ According to the data from cancer registries in India, oesophageal cancer is the second most common cancer among men and the fourth most common cancer among women. ${ }^{14}$ Nasal and paranasal cavities are among the most common sites for malignancies in nickel workers and in those with industrial exposure to fumes and organic chemicals. Lymph node in the neck may be enlarged because of primary malignant tumours or because of the metastatic spread from the cancer of head and neck region, lung, breast, stomach and testes.

\section{MATERIALS AND METHODS}

This study was conducted on 150 diagnosed cases of head and neck cancer from the ENT Department of Government Medical College and Rajindra Hospital, Patiala, Punjab, India. Detailed history of the selected patients with head and neck cancer was taken as per proforma after taking informed consent which also included history of tobacco smoke exposure, personal history and family history of head and neck cancer. Tumour data including site, subsite, grade and TNM stage were collected. Each patient was subjected to detailed clinical examination and investigation. On the basis of the above clinical examination and investigation, incidence and aetiology of head and neck cancer was calculated and
TNM staging was evaluated. All the information was entered in the predesigned proforma and analysed statistically and $\mathrm{P}$ $<0.05$ was considered significant and $\mathrm{P}<0.001$ was considered highly significant at the end of the study period.

Acceptance Criteria-

Age: All age group

Gender: Both

Healthy Volunteers: No

\section{Inclusion Criteria}

- All subjects with newly diagnosed, biopsy proven carcinoma of head and neck.

- The patient is able to understand and give informed consent (in case of minor- guardian of the patient)

\section{Exclusion Criteria}

- Patients with suspicion of head and neck cancer in which final diagnosis had not been made.

- Patients who do not have cancer of head and neck.

- Patients who have a recurrence of their cancer of head and neck.

- Patient has a psychiatric illness or developmental delay, which would interfere with understanding of the study and provision of informed consent.

\section{RESULTS}

Histopathological examination confirmed 150 patients with malignancy in the region of head and neck admitted in the ENT Department of Rajindra Hospital, Patiala. The maximum prevalence of patients with head and neck cancer was seen in the fifth decade (34.66\%) followed by sixth decade $(23.33 \%)$. Of the 150 patients with head and neck cancer included in our study 105 were men (70\%) and 45 were women (30\%), which indicate that incidence of head and neck cancer was 2.5 times higher in men as compared with women. The highest incidence of head and neck cancer reported in this study was in the persons belonging to labourer group (54 cases, $49 \%$ ) followed by farmers (25 cases, $22.72 \%$ ) and businessmen (17 cases, $15.45 \%$ ). Most of the women in this study were housewives. Poor orodental hygiene and Plummer-Vinson syndrome were found to be the most frequent predisposing factors affecting the housewives, whereas chronic habits of smoking and drinking alcohol played a major role in causing cancer in labourers, farmers and businessmen. The incidence of head and neck cancer was maximum in poor people; therefore, poor people have more risk to cancer because of their unhygienic living standards, poor orodental hygiene and poor nutrition leading to anaemia, thus Plummer-Vinson syndrome. Incidence of cancer in head and neck region was 3.6 times more in the rural area of Malwa region of Punjab as compared with the 32 cases $(21.33 \%)$ seen in the urban area. Lack of awareness to seek an early medical advice because of illiteracy and unhygienic conditions of living may be responsible for higher incidence. Cancer of oral cavity was the most common cancer seen in head and neck region (39.33\%). It was followed by the cancer of oropharynx and laryngopharynx. Approximately, $84.7 \%$ of the patients with oral cavity cancer present with growth or mass, whereas $65.7 \%$ and $85.29 \%$ of the patients with oropharyngeal and hypopharyngeal carcinoma present with dysphagia, respectively. A total of $61.5 \%$ of the patients with laryngeal carcinoma present with 
the symptom of change in voice, whereas $38.46 \%$ of them present with the symptom of lump in the neck. In oral cavity SCC maximum incidence was seen in oral tongue (16.66\%) followed by buccal mucosa (14\%), whereas in oropharyngeal SCC maximum incidence was seen in base of tongue (11.33\%) followed by retromolar trigone (6\%). In hypopharynx, maximum incidence was seen in post-cricoid region $(9.33 \%)$ followed by pyriform fossa $(5.33 \%)$. In larynx carcinoma, maximum incidence was seen in glottis region $(2 \%)$ followed by supraglottic region (1.33\%). In lymph node carcinoma, maximum incidence was occult primary (4.66\%) followed by known primary $(1.33 \%)$. In salivary glands tumour, major gland especially parotid gland showed incidence of $2 \%$ followed by minor glands (1.33\%). In nasopharynx and thyroid gland, maximum incidence was $1.33 \%$. In nose and paranasal sinuses incidence of carcinoma recorded was $2 \%$, and in ears, cervical oesophagus and mandible incidence of carcinoma was $0.66 \%$. Moderately differentiated SCC predominated in our study. In case of moderately differentiated SCC, $83.7 \%$ had oral cavity cancers and $85.7 \%$ had oropharyngeal cancers. Maximum patients presented with early tumour staging, that is T1 and T2 (87.28\%). Cases of carcinoma of nasopharynx, thyroid and oesophagus presented to us were in T2 stage (100\%).

\begin{tabular}{|c|c|c|c|c|c|c|c|}
\hline \multirow{3}{*}{$\begin{array}{l}\text { Sl. } \\
\text { No. }\end{array}$} & \multirow{3}{*}{ Site } & \multirow{2}{*}{\multicolumn{2}{|c|}{$\begin{array}{c}\text { No. of Cases } \\
\text { Males }\end{array}$}} & \multirow{2}{*}{\multicolumn{2}{|c|}{$\begin{array}{c}\text { No. of Cases } \\
\text { Females } \\
\end{array}$}} & \multirow{2}{*}{\multicolumn{2}{|c|}{$\begin{array}{c}\text { Percentage } \\
\text { Total }\end{array}$}} \\
\hline & & & & & & & \\
\hline & & No. & \% Age & No. & $\%$ Age & No. & $\%$ Age \\
\hline \multirow[t]{5}{*}{1.} & Oral Cavity & 39 & 37.1 & 20 & 44.44 & 59 & 39.33 \\
\hline & a. Buccal mucosa & 12 & 11.4 & 9 & 20 & 21 & 14 \\
\hline & b. Floor of mouth & 7 & 6.66 & 5 & 11.11 & 12 & 8 \\
\hline & c. Tongue & 19 & 18 & 6 & 13.33 & 25 & 16.66 \\
\hline & d. Lip & 1 & 0.95 & - & - & 1 & 0.66 \\
\hline \multirow[t]{5}{*}{2.} & Oropharynx & 24 & 22.85 & 11 & 24.44 & 35 & 23.33 \\
\hline & a. $\quad$ Tonsillar region & 6 & 5.71 & - & - & 6 & 4 \\
\hline & b. $\quad$ Soft palate & - & - & 3 & 6.66 & 3 & 2 \\
\hline & c. Case of tongue & 11 & 10.47 & 6 & 13.33 & 17 & 11.33 \\
\hline & d. Retromolar trigone & 7 & 6.66 & 2 & 4.44 & 9 & 6 \\
\hline \multirow[t]{3}{*}{3.} & Laryngopharynx & 11 & 10.47 & 11 & 24.44 & 22 & 14.66 \\
\hline & a. Pyriform fossa & 5 & 4.76 & 3 & 6.66 & 8 & 5.33 \\
\hline & b. Post-cricoid region & 6 & 5.71 & 8 & 17.77 & 14 & 9.33 \\
\hline \multirow[t]{3}{*}{4.} & Larynx & 7 & 6.66 & 1 & 2.22 & 8 & 5.33 \\
\hline & a. $\quad$ Supraglottic & 2 & 1.90 & - & - & 2 & 1.33 \\
\hline & b. $\quad$ Glottic & 2 & 1.90 & 1 & 2.22 & 3 & 2 \\
\hline \multirow[t]{3}{*}{5.} & Lymph Nodes & 8 & 7.61 & 3 & 6.66 & 11 & 7.33 \\
\hline & a. Occult primary & 5 & 4.76 & 2 & 4.44 & 7 & 4.66 \\
\hline & b. Known primary & 1 & 0.95 & 1 & 2.222 & 2 & 1.33 \\
\hline 6. & Salivary Glands & 3 & 2.85 & 2 & 4.44 & 5 & 3.33 \\
\hline 7. & Nasopharynx & 2 & 1.90 & - & - & 2 & 1.33 \\
\hline 8. & Thyroid Gland & - & - & 2 & 4.44 & 2 & 1.33 \\
\hline \multirow[t]{3}{*}{9.} & Nose and Paranasal Sinuses & 3 & 2.85 & - & - & 3 & 2 \\
\hline & a. Lateral wall of the nose & 2 & 1.90 & - & - & 2 & 1.33 \\
\hline & b. Maxillary antrum & 1 & 0.95 & - & - & 1 & 0.66 \\
\hline 10. & Ears & 1 & 0.95 & - & - & 1 & 0.66 \\
\hline 11. & Cervical Oesophagus & 1 & 0.95 & - & - & 1 & 0.66 \\
\hline 12. & Mandible & 1 & 0.95 & - & - & 1 & 0.66 \\
\hline
\end{tabular}

\begin{tabular}{|c|c|c|c|c|c|c|c|}
\hline Symptoms & Oral Cavity & Oropharynx & Hypopharynx & Larynx & Salivary Gland & Nasopharynx & Thyroid \\
\hline Mass/growth & 50 & 2 & - & 3 & 5 & 3 & 5 \\
\hline Non-healing ulcer & 16 & - & - & - & - & - & - \\
\hline Bleeding & 7 & - & 2 & - & - & 2 & - \\
\hline Odynophagia & 5 & 20 & 13 & 5 & - & - & 1 \\
\hline Dysphagia & - & 23 & 29 & 4 & - & - & 1 \\
\hline Lump in the neck & - & 17 & 25 & 5 & - & 3 & 3 \\
\hline Change in voice & - & - & 8 & 8 & - & - & 1 \\
\hline Mass in preauricular region & - & - & - & - & 5 & - & - \\
\hline Conductive hearing loss & \multicolumn{7}{|c|}{ Table 2. Symptoms } \\
\hline \multicolumn{7}{|l}{} \\
\hline
\end{tabular}




\begin{tabular}{|c|c|c|c|c|c|c|c|}
\hline \multirow{3}{*}{$\begin{array}{l}\text { Sl. } \\
\text { No. }\end{array}$} & \multirow{3}{*}{ Tumour Types } & \multirow{2}{*}{\multicolumn{2}{|c|}{$\begin{array}{c}\text { No. of Cases } \\
\text { Males }\end{array}$}} & \multirow{2}{*}{\multicolumn{2}{|c|}{$\begin{array}{c}\text { No. of Cases } \\
\text { Females } \\
\end{array}$}} & \multirow{2}{*}{\multicolumn{2}{|c|}{ Percentage Total }} \\
\hline & & & & & & & \\
\hline & & No. & \% Age & No. & \% Age & No. & \% Age \\
\hline \multirow[t]{5}{*}{1.} & Squamous Cell Carcinoma & 57 & 38 & 33 & 22 & 90 & 60 \\
\hline & a. Well differentiated & 19 & 12.66 & 13 & 8.66 & 32 & 21.33 \\
\hline & b. $\quad$ Moderately differentiated & 29 & 19.33 & 15 & 10 & 44 & 29.33 \\
\hline & c. $\quad$ Poorly differentiated & 8 & 5.33 & 5 & 3.33 & 13 & 8.66 \\
\hline & d. Verrucous type & 1 & 0.66 & - & - & 1 & 0.66 \\
\hline 2. & Basal cell carcinoma & 5 & 4.76 & 3 & 6.66 & 8 & 5.33 \\
\hline 3. & Basisquamous carcinoma & 3 & 2.00 & 3 & 6.66 & 6 & 4.00 \\
\hline 4. & Metastatic carcinomatous deposits & 12 & 8.00 & 8 & 5.33 & 20 & 13.33 \\
\hline \multirow[t]{5}{*}{5.} & Salivary glands & 5 & 3.33 & 2 & 1.33 & 7 & 4.66 \\
\hline & a. Adenoid cystic carcinoma & 3 & 2.0 & - & - & 3 & 2.00 \\
\hline & b. Mucoepidermoid carcinoma & 1 & 0.66 & 1 & 0.66 & 2 & 1.33 \\
\hline & c. Pleomorphic adenoma & 1 & 0.66 & - & - & 1 & 0.66 \\
\hline & d. Undifferentiated carcinoma & - & - & 1 & 0.66 & 1 & 0.66 \\
\hline \multirow[t]{3}{*}{6.} & Thyroid gland & - & - & 4 & 2.66 & 4 & 2.66 \\
\hline & a. $\quad$ Follicular carcinoma & - & - & 3 & 2.00 & 3 & 2.00 \\
\hline & b. Undifferentiated giant cell carcinoma & - & - & 1 & 0.66 & 1 & 0.66 \\
\hline \multirow[t]{2}{*}{7.} & Nose & & & & & & \\
\hline & Papillary adenocarcinoma & 1 & 0.66 & - & - & 1 & 0.66 \\
\hline \multirow[t]{3}{*}{8.} & Lymphoma & 2 & 1.90 & - & - & 2 & 1.33 \\
\hline & a. Non-Hodgkin's lymphoma & 1 & 0.66 & - & - & 1 & 0.66 \\
\hline & b. Hodgkin's lymphoma (lymphocytic predominant) & 1 & 0.66 & - & - & 1 & 0.66 \\
\hline 9. & Fibrosarcoma & 2 & 1.33 & - & - & 2 & 1.33 \\
\hline 10. & Malignant mesenchymal tumour & 2 & 1.33 & - & - & 2 & 1.33 \\
\hline 11. & Chondrosarcoma & 1 & 0.66 & - & - & 1 & 0.66 \\
\hline 12. & Sarcoma botryoides & 1 & 0.66 & - & - & 1 & 0.66 \\
\hline 13. & Meibomian & 4 & 3.8 & 3 & 6.6 & 7 & 4.66 \\
\hline
\end{tabular}

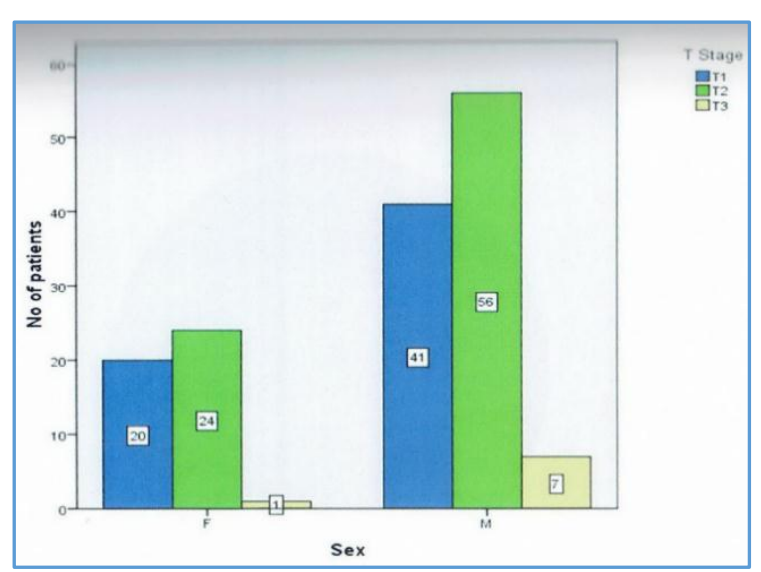

Graph 1

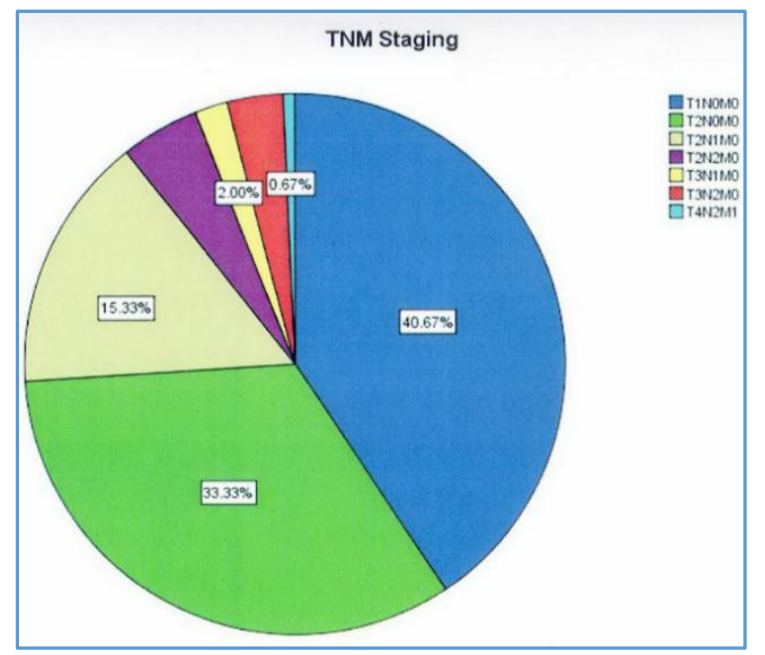

Graph 2

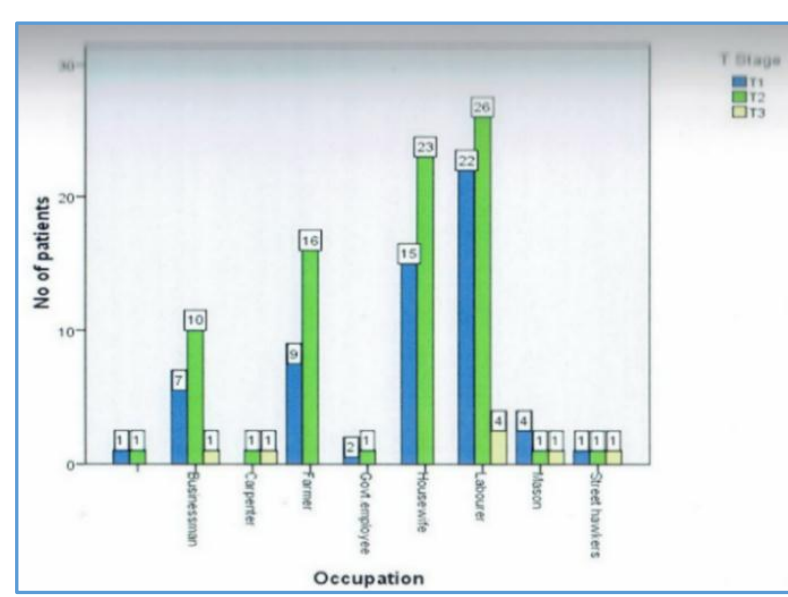

Graph 3

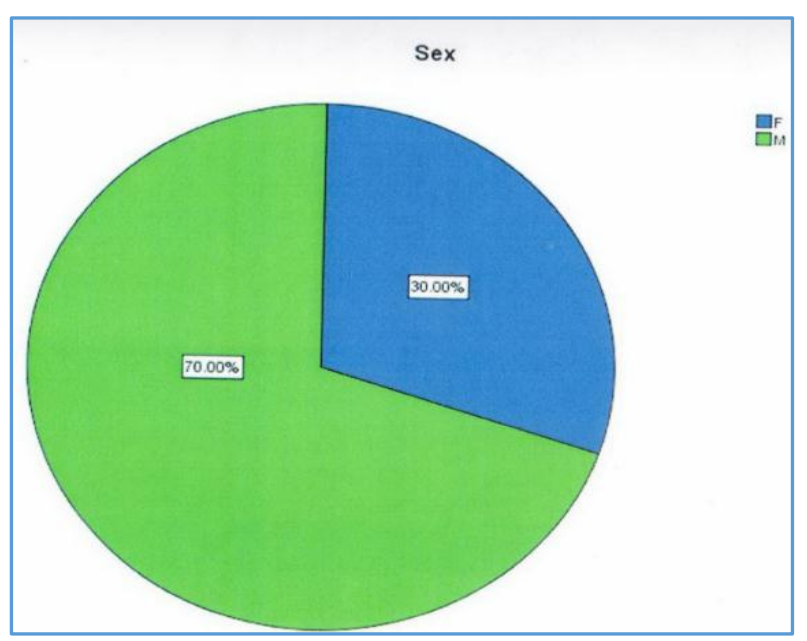

Graph 4 


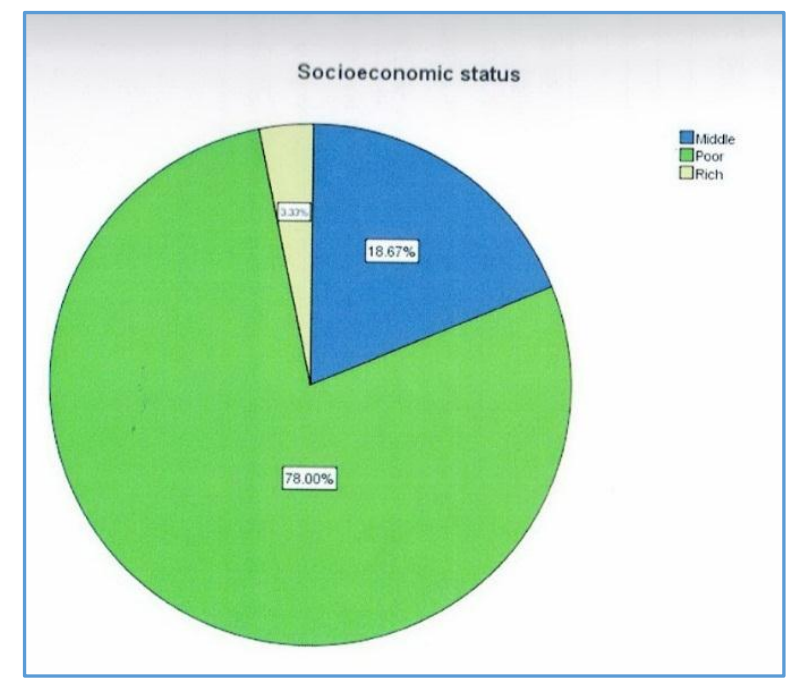

Graph 5

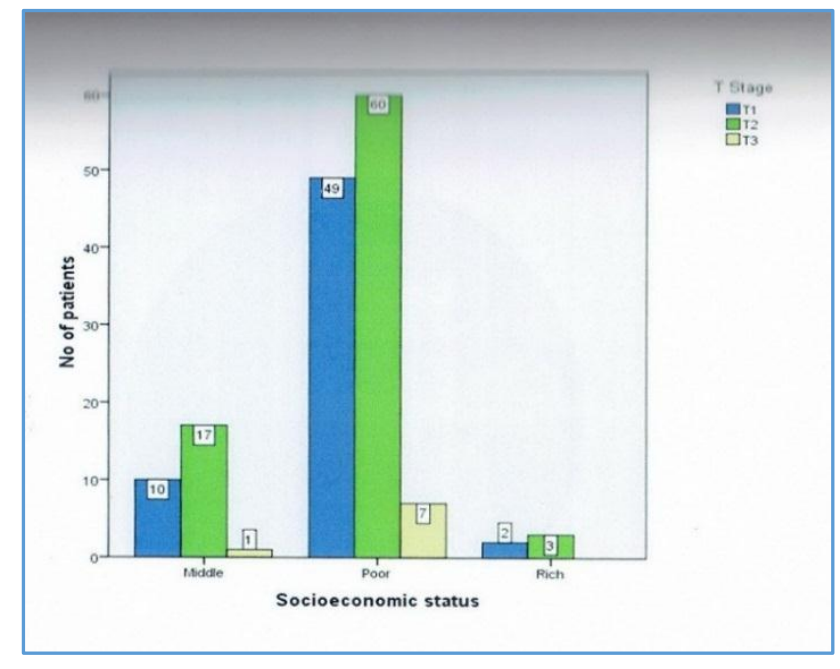

Graph 6
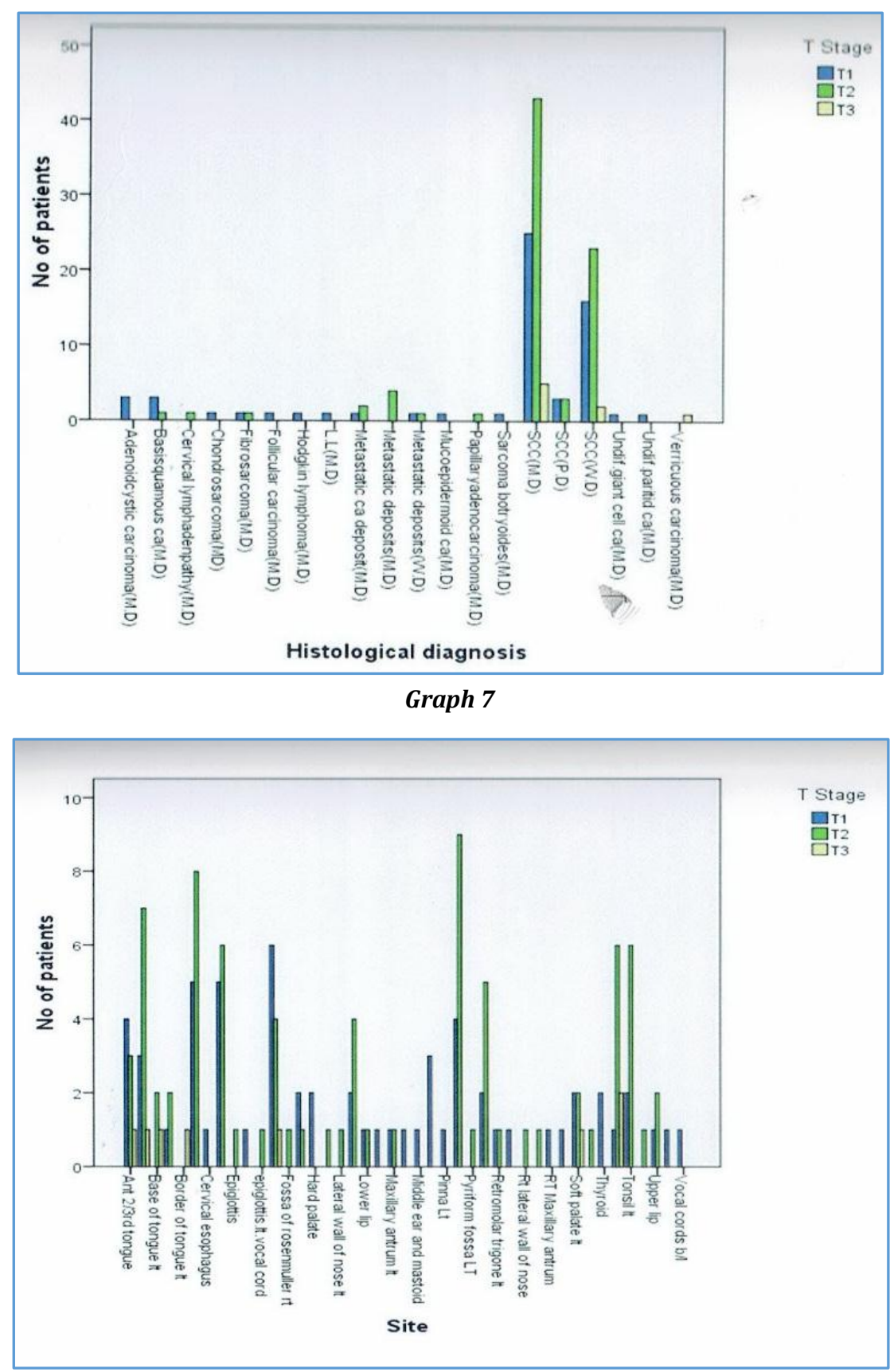

Graph 8 


\section{DISCUSSION}

In this study, maximum prevalence of patients with incidence of head and neck cancer was seen in the fifth decade (34.66\%) followed by sixth decade. The incidence of head and neck cancer decreased below the age of 30 years and above the age of 60 years. Our study was compatible with the study by Sharma et al.15 Our study comprised of 150 patients, of which 105 patients were men and 45 patients were women. These findings were in concordance with the results of various previous studies conducted in India. In our study, the most frequent site involved was oral cavity, subsite was the oral tongue $16.66 \%$ followed by buccal mucosa $14 \%$, floor of mouth and lip. Our study was congruent with the studies conducted by Dahlstrom et al, ${ }^{16}$ Wiseman et al $^{17}$ and Harris et al.18 In addition, we found that among the oral tongue growths, lateral border of tongue was most commonly involved. The dental professionals as well as ENT surgeons should be cognizant of the increasing incidence of oral tongue SCC and should consider oral tongue SCC, while evaluating patients with tongue lesions even when history of smoking and alcohol abuse was not present. The most common oropharyngeal subsite in our patients was the base of the tongue $11.33 \%$ followed by retromolar trigone $6 \%$. Dahlstrom et $\mathrm{al}^{16}$ and Wiseman et $\mathrm{al}^{17}$ also found the most common oropharyngeal subsite to be the base of the tongue followed by tonsillar fossa. First symptom in cancer oropharynx was difficulty in swallowing. Other presenting symptoms were trismus and cervical lymphadenopathy. SCC was most commonly seen in oropharynx, dominated by moderately differentiated carcinoma. Hypopharyngeal carcinoma constituted $14.66 \%$ of head and neck cancer. Cancer in most of the cases was seen arising from pyriform fossa $(9.33 \%)$ and post-cricoid (5.33\%) region. Stefani and Eells ${ }^{19}$ recorded pyriform fossa to be the most common site of origin. The development of hypopharyngeal cancers in the post-cricoid area in women in the age group of 30 to 50 years without a history of tobacco or alcohol use was associated with Plummer-Vinson syndrome, also termed as PatersonBrown-Kelly syndrome.20-22 This syndrome was characterised by hypopharyngeal webs, dysphagia, weight loss and irondeficiency anaemia. A substantial proportion of hypopharyngeal cancers could be attributable to occupational exposures. ${ }^{23}$ The most common form of clinical presentation in our present cases was dysphagia, which was seen in 19 of the 22 cases. Larynx was involved in $5.33 \%$ of the patients with head and neck cancer in our study. Jussawalla et al 24 have correlated the development of laryngeal carcinoma with smoking habits. In a study by Sharma et al, ${ }^{15}$ the prevalence of laryngeal SCC constituted $16.7 \%$ of the total HNSCC. SCC was predominant. Malignancy involving cervical lymph nodes was observed in eight cases $(7.33 \%)$, of which five patients had occult primary and two had lymphoma. Primary site in case of metastatic carcinoma of cervical lymph nodes was nasopharynx in $37.5 \%$ of the patients. In this study, the incidence of cancer in the salivary glands was 3.33\% [three cases] of the patients with head and neck cancer. In our study, parotid was commonly affected. In a study conducted in Manipur, Bhatia and Jha ${ }^{25}$ reported incidence of carcinoma of the salivary gland to be $2.9 \%$ of the patients with head and neck cancer. Nasopharynx constituted $1.33 \%$ of the patients with head and neck cancer. Sharma et al15 found nasopharyngeal carcinoma in $1.05 \%$ of the patients. In our study, women above 60 years of age presented with complaint of nasal obstruction and nasal bleeding. In our study, nasopharyngeal carcinoma involved roof of nasopharynx followed by fossa of Rosenmuller. All the cases belonged to SCC and both were moderately differentiated. Thyroid was involved in $1.33 \%$ of the patients with head and neck cancer. In our study, women dominated the incidence of thyroid carcinoma. In this study, incidence of nose and paranasal sinuses was $2 \%$. Nasal obstruction was the most common complaint because of the presence of mass in nasal cavity. In our study, only $0.66 \%$ of the patients with head and neck cancer showed symptoms involving ear and the patients presented with growth on pinna, whereas Bhatia and Jha 25 found it to be $0.8 \%$ in a study conducted by them in Manipur. In this study, incidence of oesophagus carcinoma was $0.66 \%$. Wynder et al26 concluded that excessive tobacco, alcohol consumption and dietary deficiencies can cause oesophagus cancer. In this study, patients had SCC of moderately differentiated type. ${ }^{26}$ Carcinoma of mandible constituted $0.6 \%$ of the patients with head and neck cancer. In our study, oral cavity cancers most commonly presented with mass/growth (84\%) followed by non-healing ulcer (27.3\%) and oropharyngeal cancers most commonly presented with dysphagia (65.7\%) followed by odynophagia (57.1\%). Strong suspicion was required for early diagnosis and management, even when patient was not having any history of tobacco or alcohol abuse. Dahlstrom et al ${ }^{16}$ observed that majority of patients presented with either moderately differentiated or well-differentiated SCC. In our study, it was observed that majority of patients presented with either well-differentiated or moderately differentiated SCC. The degree of differentiation was considered as one of the important prognostic factors in head and neck cancers. Welldifferentiated SCC showed good prognosis and poorly differentiated cancers showed worst prognosis. In this study, we found that maximum patients with oral cavity SCC (87.28\%) presented with early tumour staging, that is $\mathrm{T}_{1}$ and $\mathrm{T}_{2}$. In oropharyngeal SCC, maximum patients $(88.5 \%)$ presented with tumour staging- $\mathrm{T}_{1}$ and $\mathrm{T}_{2}$. Harris et al ${ }^{18}$ also reported maximum number of patients $(72 \%)$ who presented with $\mathrm{T}_{1}$ and $\mathrm{T}_{2}$ stage \%). We also acknowledge some limitations to our study. One limitation of our study was the relatively small patient cohort. Second limitation was that we did not include HPV status in our patients. High index of suspicion was required to diagnose these lesions early, even when history of smoking and drinking was absent.

\section{CONCLUSION}

This study was aimed at analysing the age, sex distribution, role of aetiological factors, extent and clinical presentation including site, subsite, TNM stage and histopathological grading. In non-smoking and non-drinking patients, sharp tooth, environmental smoke and occupational exposure may contribute to squamous cell carcinoma. High index of suspicion was required to diagnose these lesions early, even when history of smoking and drinking was absent.

\section{REFERENCES}

[1] Parkin DM, Bray F, Ferlay J, et al. Estimating the world cancer burden: globocan 2000. Int J Cancer 2001;94(2):153-6. 
[2] Islami F, Fedirko V, Tramacere I, et al. Alcohol drinking and esophageal squamous cell carcinoma with focus on light-drinkers and never-smokers: a systematic review and meta-analysis. Int J Cancer 2011;129(10):2473-84.

[3] Llewellyn CD, Linklater K, Bell J, et al. Squamous cell carcinoma of the oral cavity in patients aged 45 years and under: a descriptive analysis of 116 cases diagnosed in the south east of England from 1990 to 1997. Oral Oncol 2003;39(2):106-14.

[4] Sturgis EM, Cinciripini PM. Trends in head and neck cancer incidence in relation to smoking prevalence: an emerging epidemic of human papillomavirusassociated cancers. Cancer 2007;110(7):1429-35.

[5] Lee YC, Marron M, Benhamou S, et al. Active and involuntary tobacco smoking and upper aerodigestive tract cancer risks in a multicenter case-control study. Cancer Epidemiol Biomarkers Prev 2009;18(12):3353-61.

[6] Patel SC, Carpenter WR, Tyree S, et al. Increasing incidence of oral tongue squamous cell carcinoma in young white women, age 18 to 44 years. J Clin Oncol 2011;29(11):1488-94.

[7] Merletti F, Boffetta P, Ciccone G, et al. Role of tobacco and alcoholic beverages in the etiology of cancers of the oral cavity/oropharynx in Torino, Italy. Cancer Res 1989;49(17):4919-24.

[8] Olsen J, Sabroe S, Ipsen J, et al. Effect of combined alcohol and tobacco exposure on risk of cancer of the hypopharynx. J Epidemiol Community Health 1985;39(4):304-7.

[9] Thomas S, Wilson A. A quantitative evaluation of the aetiological role of betel quid in oral carcinogenesis. Eur J Cancer B Oral Oncol 1993;29B(4):265-71.

[10] Ferlay J, Bray F, Parkin DM, et al. GLOBOCAN 2002: cancer incidence, mortality and prevalence worldwide. Lyon, France: IARC Press 2004.

[11] Parkin DM, Whelan SL, Ferlay J, et al. Cancer incidence in five continents. Lyon, France: IARC Press 2002;8.

[12] IARC Working Group on the Evaluation of Carcinogenic Risks to Humans. Betel-quid and arecanut chewing and some areca-nut-derived nitrosamines. IARC Monographs on the evaluation of carcinogenic risks to humans 2004;85:1-334.

[13] Carpenter RJ, DeSanto LW. Cancer of the hypopharynx. Surg Clin North Am 1977;57(4):723-35.

[14] Gajalakshmi V, Swaminathan R, Shanta V, et al. An independent survey to assess completeness of registration: population based cancer registry, Chennai, India. Asian Pac J Cancer Prev 2001;2(3):179-83.
[15] Sharma M, Madan M, Manjari M, et al. Prevalence of head and neck squamous cell carcinoma (HNSCC) in our population: the clinic-pathological and morphological description of 198 cases. Int J Adv Res 2015;3(1):827-33.

[16] Dahlstrom KR, Little JA, Zafereo ME, et al. Squamous cell carcinoma of the head and neck in never smokernever drinkers: a descriptive epidemiologic study. Head Neck 2008;30(1):75-84.

[17] Wiseman SM, Swede H, Stoler DL, et al. Squamous cell carcinoma of the head and neck in nonsmokers and nondrinkers: an analysis of clinicopathologic characteristics and treatment outcomes. Ann Surg Oncol 2003;10(5):551-7.

[18] Harris SL, Kimple RJ, Hayes DN, et al. Never-smokers, never-drinkers: unique clinical subgroup of young patients with head and neck squamous cell cancers. Head Neck 2010;32(4):499-503.

[19] Stefani S, Eells RW. Carcinoma of the hypopharynx--a study of distant metastases, treatment failures, and multiple primary cancers in 215 male patients. Laryngoscope 1971;81(9):1491-8.

[20] Goldstein DP, Clark J, Gullane PJ, et al. Carcinoma of the hypopharynx. In: Genden EM, Varvares MA, (eds). Head and neck cancer: an evidence-based team approach. New York: Thieme Medical Publishers 2008:44-69.

[21] Kajanti M, Mauntylau M. Carcinoma of the hypopharynx a retrospective analysis of the treatment results over a 25-year period. Act Oncol 1990;29(7):903-7.

[22] Stell PM, Carden EA, Hibbert J, et al. Post-cricoid carcinoma. Clin Oncol 1978;4(3):215-26.

[23] Menvielle G, Luce D, Goldberg P, et al. Smoking, alcohol drinking, occupational exposures and social inequalities in hypopharyngeal and laryngeal cancer. Int J Epidemiol 2004;33(4):799-806.

[24] Jussawalla DJ, Sathe PV, Yeole BB, et al. Cancer incidence in Aurangabad City 1978-1980. Indian J Cancer 1984;21(2):55-62.

[25] Bhatia PL, Jha BK. Pattern of head and neck cancer in Manipur. Indian J Cancer 1982;19(5):241-8.

[26] Wynder EL, Hultberg S, Jacobsson F, et al. Environmental factors in cancer of the upper alimentary tract; a Swedish study with special reference to plummer-vinson (Paterson-Kelly) syndrome. Cancer 1957;10(3):470-87. 